\title{
Symposium review: Development, implementation, and perspectives of health evaluations in the United States*
}

\author{
K. L. Parker Gaddis, ${ }^{1} \dagger$ P. M. VanRaden, ${ }^{2}$ J. B. Cole, ${ }^{2}$ H. D. Norman, ${ }^{1}$ E. Nicolazzi, ${ }^{1}$ and J. W. Dürr ${ }^{1}$ \\ ${ }^{1}$ Council on Dairy Cattle Breeding, Bowie, MD 20716 \\ ${ }^{2}$ Animal Genomics and Improvement Laboratory, Agricultural Research Service, USDA, Beltsville, MD 20705
}

\begin{abstract}
The rate at which new traits are being developed is increasing, leading to an expanding number of evaluations provided to dairy producers, especially for functional traits. This review will discuss the development and implementation of genetic evaluations for direct health traits in the United States, as well as potential future developments. Beginning in April 2018, routine official genomic evaluations for 6 direct health traits in Holsteins were made available to US producers from the Council on Dairy Cattle Breeding (Bowie, MD). Traits include resistance to milk fever, displaced abomasum, ketosis, clinical mastitis, metritis, and retained placenta. These health traits were included in net merit indices beginning in August 2018, with a total weight of approximately $2 \%$. Previously, improvement of cow health was primarily made through changes to management practices or genetic selection on indicator traits, such as somatic cell score, productive life, or livability. Widespread genomic testing now allows for accelerated improvement of traits with low heritabilities such as health; however, phenotypes remain essential to the success of genomic evaluations. Establishment and maintenance of data pipelines is a critical component of health trait evaluations, as well as appropriate data quality control standards. Data standardization is a necessary process when multiple data sources are involved. Model refinement continues, including implementation of variance adjustments beginning with the April 2019 evaluation. Mastitis evaluations are submitted to Interbull along with somatic cell score for international validation and evaluation of udder health. Additional areas of research include evaluation of other breeds for direct health traits, use

Received September 30, 2019.

Accepted February 29, 2020.

*Presented as part of the Joint ADSA/Interbull Session: Breeding and Genetics Data Pipelines for Implementation of Genomic Evaluation of Novel Traits at the ADSA Annual Meeting, Cincinnati, Ohio, June 2019.

†Corresponding author: kristen.gaddis@uscdcb.com
\end{abstract}

of multiple-trait models, and evaluations for additional functional traits such as calf health and feed efficiency. Future developments will require new and continued cooperation among numerous industry stakeholders. There is more information available than ever before with which to make better selection decisions; however, this also makes it increasingly important to provide accurate and unbiased information.

Key words: genetic parameter, genomic evaluation, health trait

\section{INTRODUCTION}

The dairy industry has been very successful at improving production, achieving more than a 5 -fold increase in milk yield since the beginning of the 20th century. Through both improved management and advancing genetic selection strategies, the average dairy cow today produces over $10,000 \mathrm{~kg}$ of milk per lactation (USDA-NASS, 2018). Previous emphasis on production allowed an antagonistic genetic relationship between production and health to become increasingly apparent (e.g., Pryce et al., 1998; Rauw et al., 1998). Shifts in the dairy industry toward larger herd sizes have emphasized the importance of cows with strong resistance to diseases. Concurrently, consumer interest in animal welfare, as well as societal impacts (e.g., antibiotic usage) has grown (Boichard and Brochard, 2012).

Improvement of cow health can be achieved through several approaches. Management can be improved to provide cows with the best possible environment. Nutrition can be optimized to mitigate metabolic disorders. Unlike changes to management or nutrition, genetic improvement is appealing because its gains are cumulative and permanent. Low heritability and lack of centralized records, however, have previously precluded genetic evaluations for direct health traits in the United States.

\section{EARLY DEVELOPMENT}

Genetic improvement of disease resistance in dairy cattle has been an area of research for several decades. 
For more than 50 yr, researchers have described the genetic variation of disease resistance among animals (e.g., Hutt, 1958). Genetic improvement relies on the collection of phenotypic data, which must accumulate over many years, whether the data are collected on paper or electronically, and requires a long-term commitment to the program. Several European countries implemented such recording systems for health traits in the 1970s and 1980s, allowing the development and implementation of genetic evaluation for direct health traits. For example, Norway and Denmark have had health recording systems in place for approximately 50 yr (Frandsen, 2013; Heringstad and Østerås, 2013), whereas official health recording began in Finland and Sweden in 1982 and 1984, respectively (Emanuelson, 2013). In the United States, there were calls for a unified health recording system over $35 \mathrm{yr}$ ago (e.g., Pond et al., 1982; Wiggans, 1994); however, not much progress was made except at the research level.

In more recent years, many countries have recognized the importance of recording health data and have implemented evaluations. Austria developed a health monitoring system beginning in 2006, with these data included in breeding programs since 2011 (Egger-Danner et al., 2013). Development of a system to collect common health events in Canada was started in 2007 (Kelton and Hand, 2013). Genetic evaluation of clinical mastitis was initiated in 2014 in Canada (Koeck et al., 2012b). Evaluations for metabolic diseases and hoof health have since followed (Koeck et al., 2015; Malchiodi et al., 2017). France has evaluated clinical mastitis since 2010 (Govignon-Gion et al., 2012). In Australia, clinical observations of disease are being collected from genomic information nucleus herds to develop national health breeding values (Abdelsayed et al., 2017; Pryce et al., 2018).

In 1994, more progress toward genetic improvement of health in the United States was initiated through the use of indirect selection and indicator traits. Somatic cell score and productive life (PL) were combined with yield traits into a total net merit selection index (NM\$; VanRaden and Wiggans, 1995). Somatic cell score was incorporated to reduce the labor and health costs associated with clinical mastitis (VanRaden, 2017). Productive life provides an indirect indicator of overall health by estimating the length of time a cow remains in the milking herd, a measurement that can be affected by, among other factors, the health of the cow (VanRaden, 2017). These traits have typically been recorded routinely through the DHI system for decades, resulting in a large amount of data available to use for genetic evaluation. Improved resistance to health events has been accomplished as a result of selecting to improve indicator traits such as SCS and PL.
The availability of data on indicator traits for health should not understate the importance of recording direct health traits. Additional genetic progress is expected from direct selection for resistance to health events. Countries with mandatory recording of health events have demonstrated that genetic improvement of health traits is feasible, while also continuing to improve production efficiency (e.g., Heringstad et al., 2003; Philipsson and Lindhe, 2003). Many national evaluations (e.g., Canada, France), including those in the United States, rely on health events voluntarily reported by producers. In addition to genetic evaluation, health records provide producers with an indication of health status of the herd and present aspects of management that could be improved. More broadly, thorough health event reporting on a national or larger level can be used for benchmarking and identifying current and future areas of concern.

Clearly, one limitation in the development of direct genetic measures for health traits in the United States has been the lack of a centralized system to collect health data at a national level. Researchers at the University of Wisconsin demonstrated that producerrecorded health event data were a viable source of phenotypes for genetic evaluation if the data could be collected into a national data set (Zwald et al., 2004). In an effort to advance the development of health evaluations, the Animal Improvement Program Laboratory (now the Animal Genomics and Improvement Laboratory, AGIL; Beltsville, MD), with cooperation from industry partners and veterinary experts, developed a standardized health record in 2008 (Format 6; Cole et al., 2008). It was created to facilitate health and management data collection for research based on data available from on-farm computer systems (Cole et al., 2008). Special care was taken to avoid reference to the treatment of health events in response to industry concerns. This is in contrast to protocols in some European countries where health events are collected through the reporting of treatments administered by veterinarians (e.g., Heringstad and Østerås, 2013). Format 6 was designed to be easily extensible to accommodate the collection of new traits. It was also developed to be compatible with the lactation record (Format 4) and reproductive record (Format 5) that were already in use at the time. Since its introduction, Format 6 has undergone several revisions to clarify and improve collection of health data, with the latest revision in 2017. The current version is available at https://redmine.uscdcb .com/projects/cdcb-customer-service/wiki/Format_6.

Format 6 currently includes 20 health event codes that cover clinical mastitis, reproductive problems, metabolic disorders, and injuries, as well as 4 management codes, including body condition score, locomo- 
tion score, temperament, and milking speed. The first 100 bytes of a record are designed to follow the same structure as other data formats used by the Council on Dairy Cattle Breeding (CDCB; Bowie, MD) and include such information as animal, sire, and dam identification, herd identification number, and calving date. Following this, each record can include up to 20 individual segments, each representing a reported health event. Each segment includes the standardized health acronym, the date of the health event, and specific details related to the type of event.

No rules or regulations mandate that producers in the United States report health event incidences at a national level. Despite this, previous research has demonstrated that genetic selection for resistance to common health events is feasible using voluntarily provided data from producers (e.g., Zwald et al., 2004; Parker Gaddis et al., 2012). Several companies have developed proprietary genetic evaluations for health traits based on producer-recorded data (e.g., Vukasinovic et al., 2017; Gonzalez-Peña et al., 2019). To alleviate producer concerns of a government agency storing health data and to serve as a source of independent evaluations, CDCB developed and implemented a pipeline for the genetic and genomic evaluation of 6 common health event traits in Holsteins: hypocalcemia or milk fever (MFEV), displaced abomasum (DA), ketosis (KETO), clinical mastitis (MAST), metritis (METR), and retained placenta (RETP). These evaluations are based on producer-recorded data collected on farm. This effort also included the estimation of economic weights for the 6 health traits, as well as incorporating these traits into current selection indices.

\section{AVAILABLE DATA}

The data pipeline through which health data are currently collected is based on the DHI system. Producerrecorded health event data are collected from on-farm management systems. This information is submitted to 1 of 4 Dairy Records Processing Centers (DRPC) in the United States. The DRPC are responsible for standardizing the health event data that a producer reports to the appropriate acronyms as defined in Format 6. Although Format 6 has been available since 2008, industry-wide use did not occur until recently. Previous research resulted in the development of an extensive cross-reference dictionary for the acronyms most commonly reported by producers (Cole et al., 2006; Parker Gaddis et al., 2012). Cross-reference information for the 6 health events was provided to each DRPC to aid in the development of their own cross-reference list that is customized to match their customers' recording prac- tices. Each DRPC developed their own cross-reference dictionary assigning standardized acronyms based on the acronym and details provided by producers either independently or in collaboration with CDCB. For example, the producer-reported acronym of "RP" would be converted to "RETP" for retained placenta. It is imperative that those involved in collecting and processing these data continue to cooperate and monitor the data to ensure capture of all usable data.

Each DRPC routinely submits Format 6 health records to CDCB, which began in 2017. Initial editing is performed before inclusion in the national dairy database. Examples of these editing checks include date plausibility (e.g., health event date not before animal's birthdate); identification checks for the animal, sire, and dam; herd of the animal matches that already in the database, among many other criteria. A record passing all general editing checks is loaded into the national dairy database. Otherwise, a specific error is reported and that information is returned to the DRPC that submitted the record. Successful submission of health records is incentivized through remuneration of DRPCs for the number of usable records in the evaluation. Health data contributions are also rewarded through discounted genomic nomination fees (Council on Dairy Cattle Breeding, 2019).

Data must pass additional editing constraints to be used as phenotypic data for genetic evaluations, similar to those described in Parker Gaddis et al. (2012). Although Format 6 accepts 24 different acronyms, evaluations are only currently performed for the 6 most common health events. Current editing constraints to be included for genetic evaluations specify that the record must be from a US Holstein animal with known sire in parities 1 through 5 . Events are restricted to occurring within a specified timeframe after calving: MFEV events must occur within $30 \mathrm{~d}$ after calving; DA and KETO events must occur within $60 \mathrm{~d}$ after calving; MAST events must occur within $210 \mathrm{~d}$ after calving; METR must occur within $90 \mathrm{~d}$ after calving; and RETP must occur within $10 \mathrm{~d}$ after calving. Only one event per lactation is included. All animals must meet or exceed these trait-specific DIM requirements before being included for genetic evaluation, regardless of having a health event or being deemed healthy. If an animal did not report the health event within the specified time limit, she was deemed healthy for that trait. The limits were determined by considering those reported in the literature for similar studies (e.g., Heringstad et al., 2005; Koeck et al., 2012a), as well as by examining the data structure to ensure capture of the majority of the data. Minimum and maximum incidence constraints are applied on a herd-year basis to ensure 
Table 1. Summary statistics of health events available in the national dairy database as of August 2019

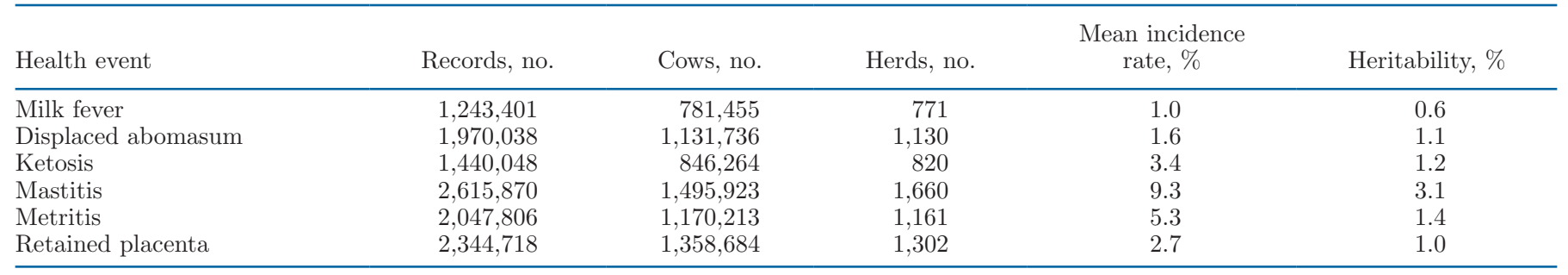

(a) that a herd is reporting a specific health event, and (b) that a herd is not using an event code to designate management practices as opposed to an actual event, respectively (e.g., many codes related to hoof care are used to track management practices rather than health events). Approximately $49 \%$ of the health events in the database are not included as phenotypes for reasons such as missing sire identification, outside parities 1 to 5 , repeated event, or the herd did not supply sufficient health records during that time. This is comparable to other national evaluations using producer-recorded data (e.g., Zwald et al., 2004; Koeck et al., 2012a). Phenotypes include data since 1991; however, the majority of data $(>85 \%)$ are since 2010 . These data are from approximately 2,000 herds throughout the United States, representing approximately $16 \%$ of US herds on DHI. Summary statistics including number of records, number of animals, and number of herds are given in Table 1 as of the most recent national tri-annual evaluation (August 2019). Total number of records was $3,771,868$, with the number of records for each specific trait varying from 1,243,401 for MFEV to $2,615,870$ for MAST. Since the initial release of health evaluations in April 2018, the number of phenotypic records used for genetic evaluation has increased by over 1.1 million, with additional records being added daily.

An incident of a health event is represented phenotypically with a score of 0 , with contemporary cows having no health event reported assumed to be healthy and given a score of 100 . Overall incidence rate for each health event is provided in Table 1 and ranges from $1.0 \%$ for MFEV to $9.3 \%$ for MAST. These values fall within an expected range compared with other similar studies. Parker Gaddis et al. (2012) summarized event incidences from numerous studies to compare the calculated incidence rate with available data. The incidence rates described herein (Table 1) fall within these incidence ranges previously summarized. Additional comparable studies using producer-recorded health data have estimated similar incidence rates to those reported herein. Neuenschwander et al. (2012) reported incidences of 2.3, 4.0, 2.6, 9.7, 3.2, and 5.9\% for MFEV, DA, KETO, MAST, METR, and RETP, respectively. Abdelsayed et al. (2017) estimated an incidence of $1.5 \%$ for metabolic disorders including MFEV, KETO, and grass tetany; $9.0 \%$ for reproductive disorders including RETP, METR, uterine infections, cystic ovarian disease, vaginal cyst, and reproductive tract trauma; and $16.1 \%$ for MAST. Higher estimates were reported by Gernand et al. (2012), although this may be attributable to the fact that the data were from 9 large herds as opposed to data on a national scale. Incidence rates from a similar study also conducted in the United States reported higher estimates for all common traits (KETO, MAST, METR, RETP) with the exception of DA, which was comparable (Vukasinovic et al., 2017). Despite this, there is always a concern of under-reporting health events, coupled with inadequate capture of data during processing. This can occur for many reasons. Health events reported by a farm can depend on the specific software used for on-farm management. Ease of reporting a specific type of event in the software (e.g., if there is a predefined acronym) may influence whether it is reported at all. Valid health events can be missed at the DRPC level if the crossreference dictionary does not include an acronym used by producers. Herd-specific practices can also affect what data are recorded. Personnel training and staffing changes can result in varied reporting consistency due to different interpretations of symptoms (ICAR, 2019). This will likely have an increasing impact as herds continue to grow in size and require additional hired staff. All of these influences can obscure the difference between herds that have very few incidences of a health event and herds that do not report a health event consistently. This is minimized as best as possible by implementing numerous levels of quality control, such as the minimum and maximum incidence constraints implemented by herd-year. It also requires that quality control standards be re-evaluated regularly, especially as more health data are being submitted.

\section{GENETIC AND GENOMIC EVALUATION}

Variance components for each health event were estimated from univariate linear animal models imple- 
mented with AIREMLF90 version 1.122 (Misztal et al., 2002). The model included fixed effects of parity, yearseason, and overall mean and random effects of herdyear $(h)$, animal $(a)$, permanent environment $(p)$, and residual (e). Season was designated as 4 categories: winter (December, January, February), spring (March, April, May), summer (June, July, August), and fall (September, October, November). Heritability $\left(h^{2}\right)$ was calculated as $h^{2}=\sigma_{a}^{2} /\left(\sigma_{a}^{2}+\sigma_{h}^{2}+\sigma_{p}^{2}+\sigma_{e}^{2}\right)$, where $\sigma^{2}$ represents the variance. Heritability estimates on the observed scale were $0.6,1.1,1.2,3.1,1.4$, and $1.0 \%$ for MFEV, DA, KETO, MAST, METR, and RETP, respectively (Table 1). These estimates align well with other estimates from the literature using linear models. The aforementioned study by Abdelsayed et al. (2017) reported heritabilities of 3,1 , and $0.2 \%$ for MAST, reproductive disorders, and metabolic disorders, respectively, among Australian Holsteins across all parities using a linear animal model. Heritability estimates from Canadian Holstein data were reported separately for first- and later-parity animals using linear animal models. Estimates among first-parity animals were higher than those reported here; however, the laterparity estimates were comparable (Jamrozik et al., 2016). Heritability estimates from threshold models are typically higher than those estimated with linear models, comparing heritabilities on the underlying scale to those on the observed scale. Heritabilities estimated using data from US animals with a threshold animal model were 8.1, 5.9, 6.9, 5.9, and $7.3 \%$ for DA, KETO, MAST, METR, and RETP, respectively (Vukasinovic et al., 2017). Higher heritabilities using threshold models have also been reported by Neuenschwander et al. (2012) and Gernand et al. (2012). These variance component estimates are used in the calculation of traditional evaluations.

\section{Traditional Evaluation}

Traditional (pedigree-based) PTA are estimated using a univariate BLUP repeatability animal model, similarly to those used for routine national genetic evaluations of other traits (VanRaden et al., 2014). The model used for traditional evaluations includes fixed effects of year-season, age at calving by parity, and a regression on inbreeding. Random effects include herdyear, permanent environment, additive genetic, and residual. Estimated heritabilities described in the previous section were used, as there were not large changes in the heritability estimates with the modifications to the model. As of the August 2019 evaluations, there were 82,678,411 pedigree records included. Estimated
PTA are presented as percentage points of resistance above or below the breed average, with positive values being favorable. Average traditional reliabilities for all animals range from $15.3 \%$ for MFEV to $23.4 \%$ for MAST but reach values of $97 \%$ or greater depending on the trait. These reliabilities are expectedly low and comparable to others reported from pedigree-based genetic evaluations (e.g., Koeck et al., 2015; Vukasinovic et al., 2017).

Despite a threshold model being theoretically more appropriate given the binary nature of these traits, many previous studies using similar traits have concluded that a linear model performs equally well (Carlén et al., 2006; Koeck et al., 2010). Using a linear model allowed for an animal model (as opposed to a sire or sire-maternal grandsire model) to be easily fitted. An animal model requires fewer assumptions (e.g., random mating) and avoids problems with extreme categories (Sorensen and Gianola, 2002; Koeck et al., 2010). A threshold animal model can help adjust for differing incidence rate but did not converge for these data. To ensure stability of the health evaluations across time as an animal accumulates health records, variance pre-adjustments were investigated for the health phenotypes. Variances and observed scale heritabilities often differ for categorical traits due to differences in incidence. The methodology was analogous to that presented in Wiggans and VanRaden (1991) and similar to that applied for livability (LIV) evaluations (a binary trait). Phenotypes were preadjusted using calving-year groups, parity number, and trait heritability. Heritability was estimated for each trait overall, and for each parity 1 through 5. The adjustment applied was as follows:

$$
x_{a d j}=100-\left[y r_{\text {mean }}+\left(x-l a c y r_{\text {mean }}\right) \times \sqrt{\left(\frac{y r_{\text {mean }}}{l a c y r_{\text {mean }}}\right)} \times \sqrt{\left(\frac{h_{a l l}^{2}}{h_{\text {lac }}^{2}}\right)},\right.
$$

where $x_{a d j}$ is the adjusted incidence indicator, $x$ is the incidence indicator $(0=$ event; $100=$ healthy or no event), $y r_{\text {mean }}$ is the mean incidence calculated by 5 -yr groups, lacyr $_{\text {mean }}$ is the mean incidence calculated by parity by 5 -yr groups, $h_{\text {all }}^{2}$ is the overall trait heritability, and $h_{\text {lac }}^{2}$ is the parity-specific heritability. If there are fewer than $3 \mathrm{yr}$ in the most recent group, these years are combined with the previous 5-yr group.

Results from the variance-adjusted data were compared with previous official results (without any variance adjustment) as well as to evaluations from first lactation only. The largest change was seen in MFEV values, with a correlation of 0.79 , whereas correlations 
between the adjusted and unadjusted evaluations for all other traits ranged from 0.92 (METR and RETP) to 0.98 (DA and KETO) among bulls with $>70 \%$ reliability born since 2000 . The standard deviation of firstlactation evaluations is expected to be about $5 \%$ less than that of all lactations due to lower reliability, and all traits with the exception of DA were closer to this expectation with the applied variance adjustment. Genetic trends were compared using correlations of PTA with birth year to automatically adjust for differences in standard deviation. For all traits, first-lactation trends agreed with the trends using adjusted data more closely than with the unadjusted data. For example, the first-lactation trend of ketosis was 0.31, compared with a trend of 0.30 in the adjusted data and 0.36 in the unadjusted data. Given the favorable results indicating that the variance-adjusted phenotypes performed better than those not using an adjustment, these variance adjustments were applied to the CDCB health evaluations beginning in April 2019.

With limited data available compared with other traits, the inclusion of foreign data from Interbull (Uppsala, Sweden) can increase the reliability of health trait evaluations. Evaluations for MAST were submitted to Interbull to be included in multiple across-country evaluation (MACE) following the implementation of the variance adjustments. Mastitis is the only direct health trait currently evaluated by Interbull, which, along with SCS, makes up the udder health trait group. Evaluation results using the variance-adjusted data were submitted to and passed Interbull validation procedures in the January 2019 test run. This also served as an additional independent test of the performance of the variance adjustments. Beginning in August 2019, MACE information is incorporated with the CDCB MAST evaluations. Restrictions on the data are put in place to ensure that foreign data are from countries providing direct MAST data. This currently includes Canada, Denmark, Finland, Sweden, France, Belgium, Switzerland, and the Netherlands. Additional restrictions are placed on breed (only Holstein currently evaluated), and bulls are excluded if the country with the most daughters only sends SCS data. Average reliability of young animals increased 3.5 points following the inclusion of Interbull data; however, this is also affected by a concurrent $9 \%$ gain in domestic data for MAST.

\section{Genomic Evaluation}

Genotypes used for genomic evaluations include the 79,294 SNP used in routine US genomic evaluations by CDCB (Wiggans et al., 2019). These SNP were se- lected based on minor allele frequency, parent-progeny conflicts, and call rate, as described in Wiggans et al. (2016). The number of genotyped animals as of the August 2019 evaluation was 2,725,350. Animals are genotyped using various platforms; however, all animals are imputed to 79,294 markers using Findhap version 3 (VanRaden et al., 2011).

Allele substitution effects are estimated from deregressed traditional PTA for the 79,294 SNP included in the routine US genomic evaluations. An infinitesimal model is used with heavy-tailed priors, where smaller effects are regressed further toward zero and markers with larger effects are regressed less to account for a non-normal distribution of marker effects (VanRaden, 2008). Genomic PTA are calculated by combining 3 terms in an index: direct genomic prediction, parent average computed from the subset of genotyped ancestors using traditional relationships, and parent average (VanRaden et al., 2009). Evaluation statistics for each health event for genotyped animals are included in Table 2 (PTA) and Table 3 (reliability), grouped by sex as well as age ("old" animals are considered those with PTA reliability greater than parent average reliability). Inclusion of genomic data increases average reliability approximately 2- to 3-fold, depending on the trait. Average genomic reliability ranges from $44 \%$ for MFEV up to $67 \%$ for MAST in young bulls. In old bulls, average genomic reliability ranges from $50 \%$ for MFEV up to $77 \%$ for MAST. Reliability gains compared with traditional reliability are largest for young bulls without progeny. Reliability estimates are largely dependent on the size of the reference population (Egger-Danner et al., 2015). The reliabilities reported herein are higher than those reported from a much smaller reference population (Abdelsayed et al., 2017). Average genomic reliabilities for MAST ranged from 23 to $33 \%$ depending on the populations (bulls, bulls with more than 5 daughters, or cows). A combined trait of reproductive disorders had average genomic reliability ranging from 9 to $15 \%$ (Abdelsayed et al., 2017). A previous study in the United States reported genomic reliabilities among various groups of animals (Vukasinovic et al., 2017). Average reliability was approximately $50 \%$ for all health traits examined among young genotyped and pedigreed females.

\section{ECONOMIC INDEX}

Two recent studies were used to estimate direct treatment costs for each health event. Liang et al. (2017) estimated direct veterinary and treatment costs, producer labor, milk loss, culling cost, extended days open, on-farm death, and discarded milk costs for health dis- 
Table 2. Summary statistics of health evaluations for genotyped animals including pedigree-based and genomic PTA

\begin{tabular}{|c|c|c|c|c|c|c|c|}
\hline Group $^{1}$ & Health event ${ }^{2}$ & \multicolumn{3}{|c|}{ Pedigree-based } & \multicolumn{3}{|c|}{ Genomic } \\
\hline \multirow[t]{4}{*}{ Males, old } & MFEV & -0.09 & -2.77 & 0.62 & -0.07 & -1.96 & 0.64 \\
\hline & KETO & 0.09 & -3.13 & 1.83 & 0.09 & -3.35 & 1.70 \\
\hline & MAST & -0.19 & -12.27 & 5.77 & -0.21 & -7.43 & 5.53 \\
\hline & METR & 0.30 & -3.84 & 3.18 & 0.30 & -3.86 & 2.53 \\
\hline \multirow{5}{*}{ Males, young } & DA & 0.26 & -2.88 & 1.30 & 0.32 & -2.63 & 1.62 \\
\hline & KETO & 0.30 & -2.16 & 1.26 & 0.36 & -2.36 & 1.64 \\
\hline & MAST & 0.05 & -7.89 & 3.91 & 0.18 & -6.57 & 5.82 \\
\hline & METR & 0.63 & -2.56 & 2.11 & 0.73 & -3.19 & 2.66 \\
\hline & RETP & 0.11 & -1.24 & 0.87 & 0.11 & -1.42 & 1.13 \\
\hline \multirow[t]{2}{*}{ Females, old } & MFEV & -0.11 & -2.59 & 0.36 & -0.11 & -1.74 & 0.50 \\
\hline & DA & 0.26 & -2.49 & 1.31 & 0.25 & -2.77 & 1.52 \\
\hline \multirow{5}{*}{ Females, young } & DA & 0.24 & -2.93 & 1.41 & 0.28 & -3.04 & 1.79 \\
\hline & KETO & 0.24 & -2.30 & 1.34 & 0.28 & -2.63 & 1.71 \\
\hline & MAST & 0.06 & -7.89 & 4.21 & 0.08 & -6.70 & 5.95 \\
\hline & METR & 0.54 & -2.80 & 2.30 & 0.67 & -2.88 & 2.71 \\
\hline & RETP & 0.09 & -1.67 & 0.92 & 0.11 & -1.80 & 1.25 \\
\hline
\end{tabular}

${ }^{1}$ Distinction between "old" and "young" animals determined by comparison of PTA reliability and parent average reliability. Old animals are those with PTA reliability greater than parent average reliability.

${ }^{2} \mathrm{MFEV}=$ milk fever; DA $=$ displaced abomasum; KETO $=$ ketosis; MAST $=$ mastitis; METR $=$ metritis; RETP $=$ retained placenta.

Table 3. Summary statistics of health evaluations for genotyped animals including pedigree-based and genomic reliability

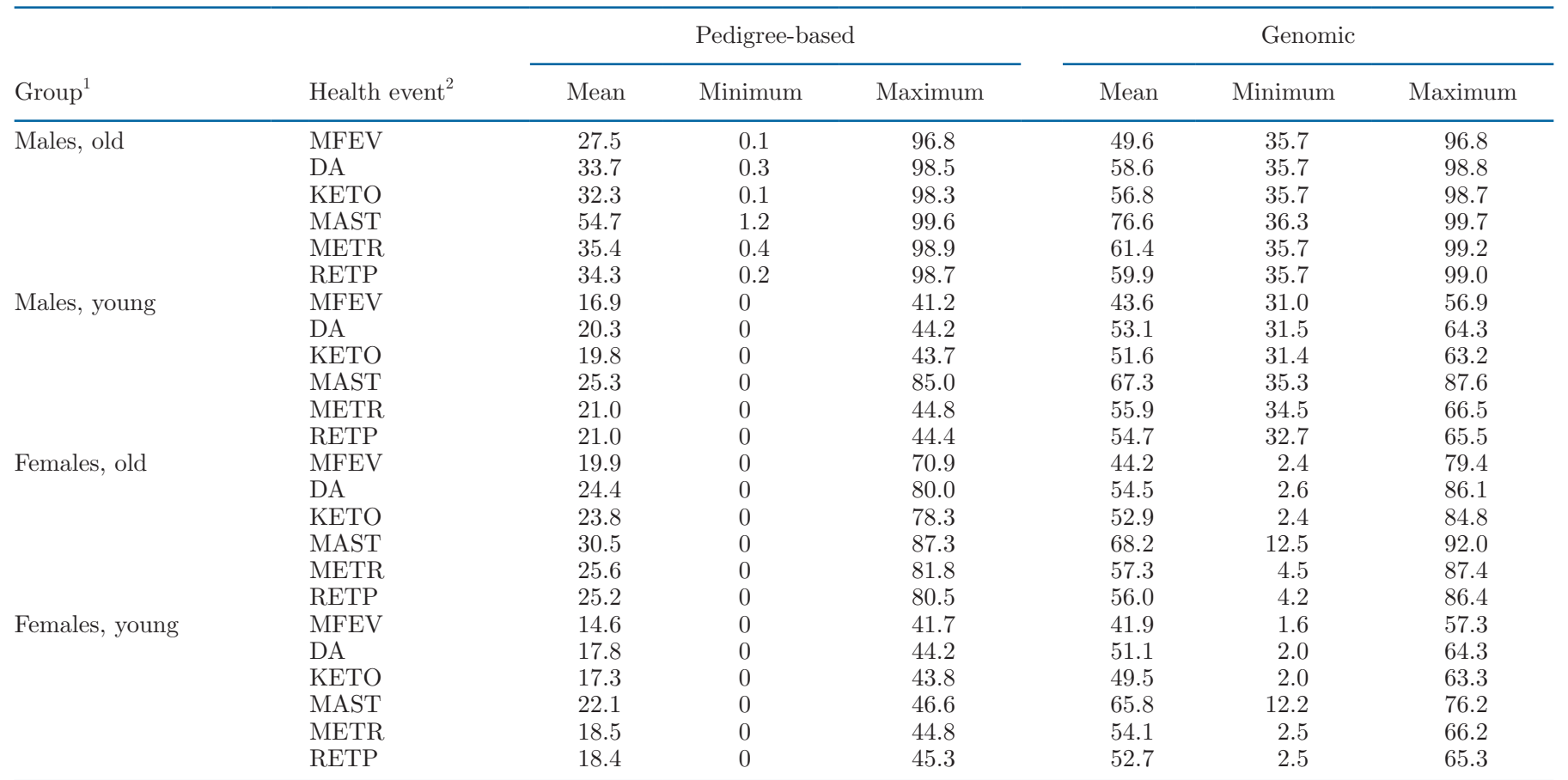

${ }^{1}$ Distinction between "old" and "young" animals determined by comparison of PTA reliability and parent average reliability. Old animals are those with PTA reliability greater than parent average reliability.

${ }^{2} \mathrm{MFEV}=$ milk fever; DA $=$ displaced abomasum; KETO = ketosis; MAST $=$ mastitis; METR $=$ metritis RETP $=$ retained placenta. 
Table 4. Economic estimates of each health event and emphasis in Net Merit $\$(\mathrm{NM} \$)$

\begin{tabular}{|c|c|c|c|c|c|}
\hline Health event & $\begin{array}{l}\text { Average direct } \\
\quad \text { cost },{ }^{1} \$\end{array}$ & $\begin{array}{l}\text { Abnormal test-day } \\
\text { adjustment, }{ }^{2} \$\end{array}$ & $\begin{array}{l}\text { Total cost used } \\
\text { in NM } \$, \$\end{array}$ & $\begin{array}{l}\text { Emphasis in health } \\
\text { index }(\mathrm{HTH} \$), \%\end{array}$ & $\begin{array}{c}\text { Emphasis in } \\
\text { NM\$, \% }\end{array}$ \\
\hline Milk fever & 38 & -4 & 34 & 3 & 0.07 \\
\hline Displaced abomasum & 178 & +19 & 197 & 39 & 0.90 \\
\hline Mastitis & 72 & +3 & 75 & 23 & 0.53 \\
\hline Metritis & 105 & +7 & 112 & 20 & 0.46 \\
\hline Retained placenta & 64 & +4 & 68 & 11 & 0.25 \\
\hline
\end{tabular}

${ }^{1}$ Average direct treatment costs from Liang et al. (2017) and Donnelly (2017).

${ }^{2}$ Estimated adjustment to direct cost resulting from abnormal test-day adjustments.

orders from veterinary and producer survey responses. Donnelly (2017) collected health treatment costs from 8 high-producing herds located in Minnesota. Table 4 includes the average of the estimated direct cost from each study. The use of direct treatment costs avoids including costs that are already accounted for in NM\$ calculations, such as correlated declines in production, fertility, and longevity.

An additional analysis was conducted to evaluate the impact of test-day production adjustments to ensure that yield losses associated with health events were fully accounted for in the economic estimates. For routine evaluations, test-day yields that are either $<60 \%$ or $>150 \%$ of predicted test-day yield are designated as abnormal and are adjusted to these limits (Wiggans et al., 2003). Farmers may also designate animals as being sick on a test day, which may result in the record not being used in the computation of lactation records, based on the International Committee for Animal Recording (ICAR) guidelines for missing results and abnormal intervals (ICAR, 2017). Milk, fat, and protein lactation yields were analyzed with abnormal and sick test-day records included at their original values compared with yields with editing and adjustments applied for a random subset of animals.

Analyzing yield traits with and without these routine adjustments indicated that most health traits resulted in a $1-\mathrm{kg}$ difference for fat and a $0.5-\mathrm{kg}$ difference for protein. Assuming a value per lactation of $\$ 1.23$ for fat and $\$ 1.32$ for protein resulted in approximately $\$ 4$ added to the direct health cost per case to account for unadjusted yield (Parker Gaddis et al., 2018). The trait affected most by this adjustment was DA, with a difference between adjusted and unadjusted yields of $2.7 \mathrm{~kg}$ of fat and $4 \mathrm{~kg}$ of protein. This resulted in $\$ 19$ added to the direct cost for DA. The larger impact estimated for DA is likely due to the severity of the event, often requiring surgery, making it more likely to be coded as sick or abnormal on test day (Parker Gaddis et al., 2018).
After accounting for the above adjustments, average cost per case of each health event was $\$ 28$ for KETO, $\$ 38$ for MFEV, $\$ 64$ for RETP, $\$ 72$ for MAST, $\$ 105$ for METR, and $\$ 178$ for DA (Table 4). These values were used when incorporating the 6 health trait evaluations into NM $\$$ beginning in August 2018 through a health traits sub-index (HTH\$). Overall, HTH\$ receives $2.3 \%$ emphasis of $\mathrm{NM} \$$, with similar emphasis in the other merit indices reported by CDCB. The correlation between the revised NM $\$$ formula released in August 2018 and the previous $\mathrm{NM} \$$ (2017) was 0.994 for recent Holstein bulls (VanRaden et al., 2018b). The largest change was seen in SCS, due to the inclusion of direct MAST. Value per lactation of PTA SCS previously included $\$ 24$ for direct premiums and $\$ 20$ for indirect costs of mastitis, including extra labor, treatment, discarded milk, and lost milk shipments due to antibiotic residue. The updated indirect cost for mastitis is $\$ 3.70$ compared with the previous $\$ 20$ assumed. This resulted in PTA SCS receiving $-3.5 \%$ emphasis in the updated $\mathrm{NM} \$$ formula compared with the previous emphasis of $-6.5 \%$ (VanRaden et al., 2018b). Percent relative emphasis for net merit traits are shown in Table 5 for the 2017 revision (before the addition of health traits) and the current (2018) revision.

\section{FUTURE DEVELOPMENTS IN US NATIONAL GENETIC EVALUATIONS}

\section{Health Evaluations for Additional Breeds}

Jersey is the second most prevalent dairy breed in the United States; however, CDCB health evaluations are currently released only for Holsteins. An increasing number of Jersey health records have been submitted by the DRPC to CDCB, with the number of records more than doubling from December 2018 to June 2019. Recent research on Jersey health evaluations (Jensen et al., 2019) found that the number of available records ranged from 39,716 for KETO to 97,507 for MAST. Av- 
Table 5. Net merit (NM) weights before (2017 revision) and including health traits (2018 revision)

\begin{tabular}{lcc}
\hline & \multicolumn{2}{c}{ Relative emphasis, \% } \\
\cline { 2 - 3 } Trait & NM\$ 2017 & NM\$ 2018 \\
\hline Milk & -1 & -1 \\
Fat & 24 & 27 \\
Protein & 18 & 17 \\
Productive life & 13 & 12 \\
SCS & -7 & -4 \\
BW composite & -6 & -5 \\
Udder composite & 7 & 7 \\
Feet/legs composite & 3 & 3 \\
Daughter pregnancy rate & 7 & 7 \\
Calving ability sub-index & 5 & 5 \\
Heifer conception rate & 1 & 1 \\
Cow conception rate & 2 & 2 \\
Livability & 7 & 7 \\
Health sub-index & NA $^{1}$ & 2 \\
\hline
\end{tabular}

${ }^{1}$ Not applicable.

erage genomic reliability in this study ranged from 29 to $35 \%$, depending on the trait, which is approximately 15 points lower than the average reliability in Holsteins. As more Jersey health data are collected, Jersey reliabilities are expected to increase. Through continued monitoring of the data and cooperation among those involved in its collection and processing, the available number of records has increased since that study, and now ranges from 77,025 for KETO to 158,556 for MAST. Health evaluations for Jerseys are currently being tested with expected publication in April 2020.

\section{Multiple-Trait Evaluations}

Multiple-trait models could be implemented for the health traits to improve evaluations. There are significant correlations among the health traits, as well as between the health traits and other routinely evaluated traits (Neuenschwander et al., 2012; Parker Gaddis et al., 2014). Table 6 provides Pearson (product-moment) correlations between PTA for the 6 health traits and PTA for other traits included in NM\$. Notable signifi- cant PTA correlations were estimated with PL and LIV, SCS, and reproductive traits. There are also significant $(P<0.05)$ PTA correlations between biologically relevant health traits such as RETP and METR (0.60) or DA and KETO (0.68). Additional significant $(P<0.05)$ PTA correlations were identified between METR and MAST (0.19), KETO and METR (0.43), and METR and DA (0.32). Using a multiple-trait model, especially when one trait has a large amount of historical data, may improve the evaluations (e.g., Koeck et al., 2015). One example of this would be evaluating MAST and SCS in a multiple-trait model. The correlation between PTA MAST and PTA SCS is approximately -0.78 , and SCS has a much larger number of records. Another correlated trait that is commonly included in MAST evaluations is udder depth (e.g., Jamrozik et al., 2013), which was found to have a significant correlation with PTA MAST of approximately 0.33 in our data. Other indicator traits that are easier to collect or less ambiguous to define could also be incorporated with a multiple-trait model; for example, BHB could be used as an indicator of ketosis or fat-to-protein ratio as an indication of energy balance (e.g., Koeck et al., 2014). Further work includes analysis of multiple-trait models, as the benefits of using multiple-trait models with the CDCB health traits need to be quantified.

\section{New Trait Development}

Functional trait development includes more than the 6 direct health traits recently released. Cow livability was first introduced in August 2016; however, heifer mortality also has a significant effect on producer profitability and management. A recent estimate of preweaning heifer mortality was $6 \%$ (USDA, 2018). The vast majority of these deaths result from either digestive disease or respiratory problems (USDA, 2018). In 2015 , the estimated cost of dairy calf deaths was $\$ 327.3$ million (USDA, 2017). Heritability of heifer livability was previously estimated to be $0.4 \%$ (VanRaden et al., 2016), and the number of heifer records currently

Table 6. Pearson (product-moment) correlations between PTA of health traits and PTA of other traits ${ }^{1}$ included in Net Merit $\$(\mathrm{NM} \$)$

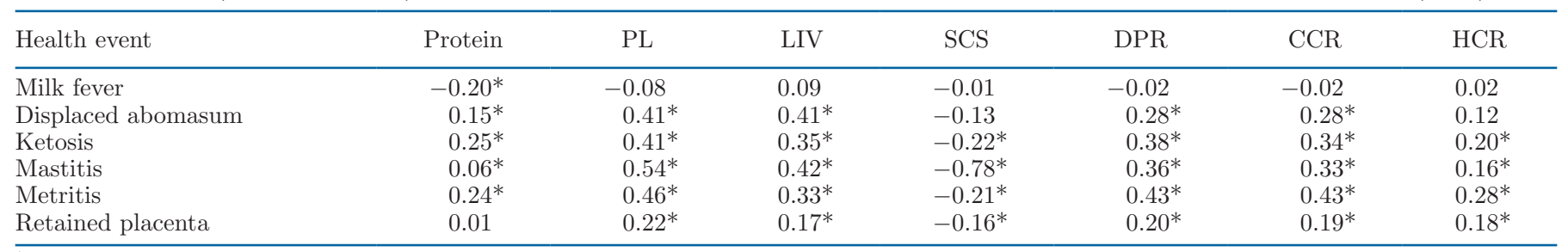

${ }^{1} \mathrm{PL}=$ productive life; $\mathrm{LIV}=$ livability; $\mathrm{DPR}=$ daughter pregnancy rate; $\mathrm{CCR}=$ cow conception rate; $\mathrm{HCR}=$ heifer conception rate. $* P<0.05$. 
available has grown to over 4.4 million. Recent research by AGIL scientists has shown that genetic evaluation of heifer livability is feasible. Despite its low heritability, the significant economic impact of heifer livability makes it a trait likely to be implemented in the future.

Heifer livability utilizes data that is already routinely collected through the DHI system. Implementation of other new traits, such as feed efficiency, requires the development of new data pipelines. Implementation of genetic evaluations for feed efficiency has been precluded by the difficulty and expense in collecting the data. Feed costs are the largest single expense of a dairy producer, and heritability estimates are low to moderate (0.14; VanRaden et al., 2018a). Feed efficiency could receive up to $16 \%$ emphasis if included in NM\$. Work is ongoing at multiple locations across the United States to continue data collection and store these data in the national dairy database to implement genetic evaluations for feed efficiency. Despite the best efforts at a national level, traits such as feed efficiency that have extremely limited data, likely require collaboration on an international level. Development of new data pipelines must consider numerous aspects including trait definition, quality control, and standardization to ensure the quality of genetic evaluations produced from this new data.

\section{CONCLUSIONS}

Selection for a robust dairy cow that has high production, becomes pregnant easily, produces a healthy calf, and resists succumbing to disease is most desirable and profitable. Development of genetic evaluations for direct health traits has spanned many years and the methodologies are continually being improved upon. Data pipelines had to be developed before the implementation of health evaluations, and the maintenance of pipelines is critical for the continuation of data flow. The US dairy industry is developing more functional traits for genetic evaluation. Some of these new traits rely on data collected through traditional means, whereas others require the creation of new data pipelines.

\section{ACKNOWLEDGMENTS}

Cole and VanRaden were supported by appropriated project 8042-31000-101-00-D, "Improving Genetic Predictions in Dairy Animals Using Phenotypic and Genomic Information," of the Agricultural Research Service of the USDA (Washington, DC). Dairy producers and industry contributors are thanked for providing phenotypic, genomic, and pedigree data. Mention of trade names or commercial products in this article is solely for the purpose of providing specific information and does not imply recommendation or endorsement by the USDA. The authors have not stated any conflicts of interest.

\section{REFERENCES}

Abdelsayed, M., M. Haile-Mariam, and J. E. Pryce. 2017. Genetic parameters for health traits using data collected from genomic information nucleus herds. J. Dairy Sci. 100:9643-9655. https:// doi.org/10.3168/jds.2017-12960.

Boichard, D., and M. Brochard. 2012. New phenotypes for new breeding goals in dairy cattle. Animal 6:544-550. https://doi.org/10 $.1017 /$ S1751731112000018.

Carlén, E., U. Emanuelson, and E. Strandberg. 2006. Genetic evaluation of mastitis in dairy cattle using linear models, threshold models, and survival analysis: A simulation study. J. Dairy Sci. 89:4049-4057. https://doi.org/10.3168/jds.S0022-0302(06)72448 $-1$.

Cole, J. B., D. J. Null, and L. R. Bacheller. 2008. A data exchange format and national database for producer-recorded health event data from on-farm management software. J. Dairy Sci. 91(E Suppl. 1):2-3. (Abstr.)

Cole, J. B., A. H. Sanders, and J. S. Clay. 2006. Use of producerrecorded health data in determining incidence risks and relationships between health events and culling. J. Dairy Sci. 89(Suppl. 1):10. (Abstr.)

Council on Dairy Cattle Breeding. 2019. Council on Dairy Cattle Breeding Service Fee Schedule. Accessed February 4, 2020. https: //redmine.uscdcb.com/attachments/download/7859/CDCB-Fee -Schedule-Update-12-18-2019.pdf.

Donnelly, M. 2017. Genetic control of health treatment costs for Holsteins in 8 high-performance dairies. MS Thesis. Department of Animal Science, University of Minnesota, St. Paul.

Egger-Danner, C., J. B. Cole, J. E. Pryce, N. Gengler, B. Heringstad, A. Bradley, and K. F. Stock. 2015. Invited review: Overview of new traits and phenotyping strategies in dairy cattle with a focus on functional traits. Animal 9:191-207. https://doi.org/10.1017/ S1751731114002614.

Egger-Danner, C., W. Obritzhauser, C. Fuerst, B. Grassauer, K. Zottl, K. Fuchs, and B. Fuerst-Waltl. 2013. Aspects of validation and data quality based on veterinary diagnoses. Pages 117-128 in ICAR Technical Series no. 17, Aarhus, Denmark. International Committee for Animal Recording (ICAR), Rome, Italy.

Emanuelson, U. 2013. Validation of the Nordic disease databases. Pages 101-108 in ICAR Technical Series no. 17, Aarhus, Denmark. International Committee for Animal Recording (ICAR), Rome, Italy.

Frandsen, J. 2013. Presentation of Danish system of registration and use of health data. Pages 13-20 in ICAR Technical Series no. 17, Aarhus, Denmark. International Committee for Animal Recording (ICAR), Rome, Italy.

Gernand, E., P. Rehbein, U. U. von Borstel, and S. König. 2012. Incidences of and genetic parameters for mastitis, claw disorders, and common health traits recorded in dairy cattle contract herds. J. Dairy Sci. 95:2144-2156. https://doi.org/10.3168/jds.2011-4812.

Gonzalez-Peña, D., N. Vukasinovic, J. J. Brooker, C. A. Przybyla, and S. K. DeNise. 2019. Genomic evaluation for calf wellness traits in Holstein cattle. J. Dairy Sci. 102:2319-2329. https://doi.org/10 $.3168 /$ jds.2018-15540.

Govignon-Gion, A., R. Dassonneville, G. Balloche, and V. Ducrocq. 2012. Genetic evaluation of mastitis in dairy cattle in France. Pages 121-126 in Interbull Bulletin No. 46, Cork, Ireland.

Heringstad, B., Y. M. Chang, D. Gianola, and G. Klemetsdal. 2005. Genetic analysis of clinical mastitis, milk fever, ketosis, and retained placenta in three lactations of Norwegian red cows. J. 
Dairy Sci. 88:3273-3281. https://doi.org/10.3168/jds.S0022 -0302(05)73010-1.

Heringstad, B., and O. Østerås. 2013. More than 30 years of health recording in Norway. Pages 39-46 in ICAR Technical Series no. 17, Aarhus, Denmark. International Committee for Animal Recording (ICAR), Rome, Italy.

Heringstad, B., R. Rekaya, D. Gianola, G. Klemetsdal, and K. A. Weigel. 2003. Genetic change for clinical mastitis in Norwegian cattle: A threshold model analysis. J. Dairy Sci. 86:369-375. https://doi .org/10.3168/jds.S0022-0302(03)73615-7.

Hutt, F. B. 1958. Genetic resistance to disease in domestic animals. In Genetic Resistance to Disease in Domestic Animals. Cornell University Press, Ithaca, NY.

ICAR. 2017. ICAR Recording Guidelines Section 2 - Guidelines for Dairy Cattle Milk Recording. Rome, Italy. Accessed Jun. 17, 2019. https://www.icar.org/Guidelines/02-Overview-Cattle-Milk -Recording.pdf.

ICAR. 2019. ICAR Recording Guidelines Section 7: Guidelines for Health, Female Fertility, Udder Health, and Claw Health Traits in Bovine. Rome, Italy. Accessed Jun. 17, 2019. https://www.icar .org/Guidelines/07-Bovine-Functional-Traits.pdf.

Jamrozik, J., A. Koeck, G. J. Kistemaker, and F. Miglior. 2016. Multiple-trait estimates of genetic parameters for metabolic disease traits, fertility disorders, and their predictors in Canadian Holsteins. J. Dairy Sci. 99:1990-1998. https://doi.org/10.3168/jds .2015-10505.

Jamrozik, J., A. Koeck, F. Miglior, G. J. Kistemaker, and F. S. Schenkel. 2013. Genetic and genomic evaluation of mastitis resistance in Canada. Pages 43-51 in Proc. Interbull Meeting. Nantes, France. Interbull, Uppsala, Sweden.

Jensen, L., K. L. Parker Gaddis, and H. D. Norman. 2019. Extending genomic evaluations to direct health traits in Jerseys. J. Dairy Sci. 102(Suppl. 1):257-258. (Abstr.)

Kelton, D. F., and K. Hand. 2013. Validation, use and interpretation of health data: an epidemiologist's perspective. Pages 129-134 in ICAR Technical Series no. 17, Aarhus, Denmark. International Committee for Animal Recording (ICAR), Rome, Italy.

Koeck, A., C. Egger-Danner, C. Fuerst, W. Obritzhauser, and B. Fuerst-Waltl. 2010. Genetic analysis of reproductive disorders and their relationship to fertility and milk yield in Austrian Fleckvieh dual-purpose cows. J. Dairy Sci. 93:2185-2194. https://doi.org/10 $.3168 /$ jds.2009-2570.

Koeck, A., J. Jamrozik, G. J. Kistemaker, F. S. Schenkel, R. K. Moore, D. M. Lefebvre, D. F. Kelton, and F. Miglior. 2015. Development of genetic evaluations for metabolic disease traits for Canadian dairy cattle. Pages 76-79 in Interbull Bulletin No. 49. Orlando, FL. Interbull, Uppsala, Sweden.

Koeck, A., J. Jamrozik, F. S. Schenkel, R. K. Moore, D. M. Lefebvre, D. F. Kelton, and F. Miglior. 2014. Genetic analysis of milk $\beta$-hydroxybutyrate and its association with fat-to-protein ratio, body condition score, clinical ketosis, and displaced abomasum in early first lactation of Canadian Holsteins. J. Dairy Sci. 97:72867292. https://doi.org/10.3168/jds.2014-8405.

Koeck, A., F. Miglior, D. F. Kelton, and F. S. Schenkel. 2012a. Health recording in Canadian Holsteins: data and genetic parameters. J. Dairy Sci. 95:4099-4108. https://doi.org/10.3168/jds.2011-5127.

Koeck, A., F. Miglior, D. F. Kelton, and F. S. Schenkel. 2012b. Short communication: Genetic parameters for mastitis and its predictors in Canadian Holsteins. J. Dairy Sci. 95:7363-7366. https://doi .org/10.3168/jds.2012-5648.

Liang, D., L. M. Arnold, C. J. Stowe, R. J. Harmon, and J. M. Bewley. 2017. Estimating US dairy clinical disease costs with a stochastic simulation model. J. Dairy Sci. 100:1472-1486. https://doi.org/10 $.3168 /$ jds.2016-11565.

Malchiodi, F., A. Koeck, S. Mason, A. M. Christen, D. F. Kelton, F. S. Schenkel, and F. Miglior. 2017. Genetic parameters for hoof health traits estimated with linear and threshold models using alternative cohorts. J. Dairy Sci. 100:2828-2836. https://doi.org/10.3168/jds .2016-11558.

Misztal, I., S. Tsuruta, T. Strabel, B. Auvray, T. Druet, and D. H. Lee. 2002. BLUPF90 and related programs (BGF90). Pages 1-2 in
Proc. 7th World Congr. Genet. Appl. Livest. Prod., Montpellier, France. Editions Quae, Montpellier, France.

Neuenschwander, T. F.-O., F. Miglior, J. Jamrozik, O. Berke, D. F. Kelton, and L. R. Schaeffer. 2012. Genetic parameters for producer-recorded health data in Canadian Holstein cattle. Animal 6:571-578. https://doi.org/10.1017/S1751731111002059.

Parker Gaddis, K. L., J. B. Cole, J. S. Clay, and C. Maltecca. 2012. Incidence validation and relationship analysis of producer-recorded health event data from on-farm computer systems in the United States. J. Dairy Sci. 95:5422-5435. https://doi.org/10.3168/jds .2012-5572.

Parker Gaddis, K. L., J. B. Cole, J. S. Clay, and C. Maltecca. 2014. Genomic selection for producer-recorded health event data in US dairy cattle. J. Dairy Sci. 97:3190-3199. https://doi.org/10.3168/ jds.2013-7543.

Parker Gaddis, K. L., M. E. Tooker, J. R. Wright, J. H. Megonigal, J. S. Clay, J. B. Cole, and P. M. VanRaden. 2018. Development of national genomic evaluations for health traits in U.S. Page 594 in Proc. 11th World Congr. Genet. Appl. Livest. Prod., Auckland, New Zealand.

Philipsson, J., and B. Lindhe. 2003. Experiences of including reproduction and health traits in Scandinavian dairy cattle breeding programmes. Livest. Prod. Sci. 83:99-112. https://doi.org/10.1016/ S0301-6226(03)00047-2.

Pond, W. G., R. A. Merkel, L. D. McGilliard, and V. J. Rhodes. 1982. Animal Agriculture: Research needs to meet the 21st century. Westview Press, Boulder, CO.

Pryce, J. E., R. J. Esslemont, R. Thompson, R. F. Veerkamp, M. A. Kossaibati, and G. Simm. 1998. Estimation of genetic parameters using health, fertility and production data from a management recording system for dairy cattle. Anim. Sci. 66:577-584. https:// doi.org/10.1017/S1357729800009152.

Pryce, J. E., T. T. T. Nguyen, M. Axford, G. Nieuwhof, and M. Shaffer. 2018. Symposium review: Building a better cow-The Australian experience and future perspectives. J. Dairy Sci. 101:37023713. https://doi.org/10.3168/jds.2017-13377.

Rauw, W. M., E. Kanis, E. N. Noordhuizen-Stassen, and F. J. Grommers. 1998. Undesirable side effects of selection for high production efficiency in farm animals: A review. Livest. Prod. Sci. 56:1533. https://doi.org/10.1016/S0301-6226(98)00147-X.

Sorensen, D., and D. Gianola. 2002. Likelihood, Bayesian, and MCMC Methods in Quantitative Genetics. Springer-Verlag, New York, NY.

USDA. 2017. Cattle and calf death loss in the United States due to predator and nonpredator causes, 2015. \#745.1217. USDA-Animal and Plant Health Inspection Service-Veterinary Services- Center for Epidemiology and Animal Health-National Animal Health Monitoring System (USDA-APHIS-VS-CEAH-NAHMS), Fort Collins, CO.

USDA. 2018. Dairy 2014, Health and management practices on U.S. dairy operations, 2014. \#696.0218. USDA-Animal and Plant Health Inspection Service-Veterinary Services-Center for Epidemiology and Animal Health-National Animal Health Monitoring System (USDA-APHIS-VW-CEAH-NAHMS), Fort Collins, CO.

USDA-NASS (National Agricultural Statistics Service). 2018. Statistics by subject-National statistics for milk. Accessed Aug. 1, 2019. https://www.nass.usda.gov/Statistics_by_Subject/index .php?sector=ANIMALS\%20\&\%20PRODUCTS.

VanRaden, P. M. 2008. Efficient methods to compute genomic predictions. J. Dairy Sci. 91:4414-4423. https://doi.org/10.3168/jds .2007-0980.

VanRaden, P. M. 2017. Net merit as a measure of lifetime profit: 2017 revision. AIP Research Report NM\$6 (2-17). Beltsville, MD. Accessed Aug. 12, 2019. https://aipl.arsusda.gov/reference/nmcalc -2017-htm.

VanRaden, P., J. O'Connell, E. Connor, M. VandeHaar, R. Tempelman, and K. Weigel. 2018a. Including feed intake data from U.S Holsteins in genomic prediction. Page 125 in Proc. 11th World Congr. Genet. Appl. Livest. Prod., Auckland, New Zealand.

VanRaden, P. M., J. B. Cole, and K. L. Parker Gaddis. 2018b. Net merit as a measure of lifetime profit: 2018 revision. AIP Research 
Report NM\$7 (5-18). Beltsville, MD. Accessed Aug. 12, 2019. https://aipl.arsusda.gov/reference/nmcalc-2018.htm.

VanRaden, P. M., J. R. O'Connell, G. R. Wiggans, and K. A. Weigel. 2011. Genomic evaluations with many more genotypes. Genet. Sel. Evol. 43:10. https://doi.org/10.1186/1297-9686-43-10.

VanRaden, P. M., M. E. Tooker, J. R. Wright, C. Sun, and J. L. Hutchison. 2014. Comparison of single-trait to multi-trait national evaluations for yield, health, and fertility. J. Dairy Sci. 97:79527962. https://doi.org/10.3168/jds.2014-8489.

VanRaden, P. M., C. P. Van Tassell, G. R. Wiggans, T. S. Sonstegard, R. D. Schnabel, J. F. Taylor, and F. S. Schenkel. 2009. Invited review: Reliability of genomic predictions for North American Holstein bulls. J. Dairy Sci. 92:16-24. https://doi.org/10.3168/jds 2008-1514.

VanRaden, P. M., and G. R. Wiggans. 1995. Productive life evaluations: Calculation, accuracy, and economic value. J. Dairy Sci. 78:631-638. https://doi.org/10.3168/jds.S0022-0302(95)76674-7.

VanRaden, P. M., J. R. Wright, M. E. Tooker, and H. D. Norman. 2016. Value of selecting for cow and calf livability. Pages 30-33 in Interbull Bulletin No. 50. Puerto Varas, Chile.

Vukasinovic, N., N. Bacciu, C. A. Przybyla, P. Boddhireddy, and S. K. DeNise. 2017. Development of genetic and genomic evaluation for wellness traits in US Holstein cows. J. Dairy Sci. 100:428-438. https://doi.org/10.3168/jds.2016-11520.
Wiggans, G. R. 1994. Meeting the needs at the national level for genetic evaluation and health monitoring. J. Dairy Sci. 77:1976-1983. https://doi.org/10.3168/jds.S0022-0302(94)77143-5.

Wiggans, G. R., T. Cooper, P. VanRaden, C. Van Tassell, D. Bickhart, and T. Sonstegard. 2016. Increasing the number of single nucleotide polymorphisms used in genomic evaluation of dairy cattle. J. Dairy Sci. 99:4504-4511. https://doi.org/10.3168/jds.2015-10456.

Wiggans, G. R., and P. M. VanRaden. 1991. Method and effect of adjustment for heterogeneous variance. J. Dairy Sci. 74:4350-4357. https://doi.org/10.3168/jds.S0022-0302(91)78631-1.

Wiggans, G. R., P. M. VanRaden, D. J. Null, and J. B. Cole. 2019 Genomic predictions using more markers and gene tests. J. Dairy Sci. 102(Suppl. 1):397. (Abstr.)

Wiggans, G. R., P. M. VanRaden, and J. C. Philpot. 2003. Technical note: Detection and adjustment of abnormal test-day yields. J. Dairy Sci. 86:2721-2724. https://doi.org/10.3168/jds.S0022 $-0302(03) 73868-5$

Zwald, N. R., K. A. Weigel, Y. M. Chang, R. D. Welper, and J. S. Clay. 2004. Genetic selection for health traits using producerrecorded data. I. Incidence rates, heritability estimates, and sire breeding values. J. Dairy Sci. 87:4287-4294. https://doi.org/10 .3168/jds.S0022-0302(04)73573-0. 